\title{
SUBCLINICAL OPERATING MICROSCOPE RETINOPATHY: THE USE OF STATIC PERIMETRY IN ITS DETECTION
}

\author{
ABDEL F. A. ARAFAT ${ }^{1}$, GORDON N. DUTTON ${ }^{2}$ and WILLIAM N. WYKES ${ }^{3}$ \\ Irbid, Jordan and Glasgow
}

\begin{abstract}
SUMMARY
Focal retinal pathology and dysfunction as a sequel to manifest damage due to operating microscope illumination is well recognised. We wished to determine whether retinal dysfunction could be identified in the absence of clinically visible lesions. We therefore have conducted a prospective controlled study on 36 patients undergoing cataract surgery and 27 control subjects. A Wild M690 zoom operating microscope was used for each procedure. No filters were used. The Humphrey visual field equipment was employed to determine threshold retinal sensitivity at predetermined loci above and below fixation in both groups. No clinically visible retinal lesions were seen in any patient. However, post-operative investigation revealed a statistically significant depression in retinal sensitivity at points most exposed to operating microscope illumination $(p<0.05)$. This was most noticeable following longer total operating times and in patients with the longest time intervals between lens extraction and completion of the procedure. It is concluded that operating microscope position and centration, and the position of the eye, should be adjusted to place the image of the illuminating element away from the foveola. Also retinal illumination should be kept to a minimum, particularly after an intraocular lens has been implanted.
\end{abstract}

Operating microscope light-induced injury was first documented clinically in 1983 in a report by McDonald and Irvine. ${ }^{1}$ Since then many authors have reported this injury following different ophthalmic procedures including cataract extraction (with and without intraocular lens implantation), ${ }^{2-9}$ refractive surgical procedure, ${ }^{10}$ combined penetrating keratoplasty with cataract extraction and intraocular lens implantation ${ }^{11,12}$ and pars plana vitrectomy. ${ }^{13}$ All of these reports describe the presence of a

From: 'Department of Ophthalmology, Faculty of Medicine, Jordan University of Science and Technology, Irbid, Jordan; ${ }^{2}$ Tennent Institute of Ophthalmology, Western Infirmary, Glasgow, UK; ${ }^{3}$ Department of Ophthalmology, Southern General Hospital, Glasgow, UK.

Correspondence to: Dr Abdel Fattah Arafat, FRCS, FRCOphth, Assistant Professor of Ophthalmology, Faculty of Medicine, Jordan University of Science and Technology, Irbid, Jordan. visible retinal lesion. Brod and colleagues ${ }^{14,15}$ have shown that the focus of illumination and thus the site of potential retinal damage engendered by the operating microscope varies with the position and centration of the microscope and the degree to which the eye is rotated at the time of surgery. In this study we used vertical static profile perimetry to investigate the possibility that the operating microscope light may impair retinal function after cataract extraction in the absence of a manifest retinal burn.

\section{MATERIALS AND METHODS}

Patients undergoing cataract extraction with intraocular lens implantation at the Southern General Hospital, Glasgow, between 25 April and 3 July 1990 were investigated. Patients with a history of glaucoma, age-related macular degeneration, myopia of more than 5 dioptres or other ocular disease which may produce visual field defects were excluded from the study. The same operating microscope (Wild M690) was used for all operations.

An International Light Photometer IL700 with a SEDO38/Y/R detector calibrated in candelas per square metre was used to measure the illuminance of the operating microscope light. The illuminance produced by the microscope lamp measured with the illuminance setting on maximum (just below the red mark) was $3.3 \times 10^{5} \mathrm{Cd} / \mathrm{m}^{2}$. No filters were used.

At operation the operating microscope was set with vertical viewing and illumination and was centred over the eye, which was rotated inferiorly using a bridle suture approximating to position 3 in the experiment by Brod et $a l .{ }^{15}$ in which the microscope light became focused inferior to the foveola with a centre $6.5^{\circ}$ from fixation. The total operating time was recorded to the nearest minute and was divided into (1) speculum insertion to nucleus extraction time, or pre-extraction time, and (2) nucleus extraction to speculum removal time, or post-extraction time.

Patients were given a posterior chamber intraocular lens implant unless operating circumstances dictated otherwise. During the second or third post-operative week, full ophthalmic examination and static field perimetry 
employing a full threshold strategy were performed with full correction of the current refractive error including a 3 dioptre add. Patients who had opacities in the media sufficient to interfere with the results of perimetry were excluded, together with those who had age-related macular degeneration of other fundus abnormalities which could interfere with the results of perimetry. A customdesigned program using the Allergan-Humphrey automated static perimeter (Fig. 1) was devised. The program was designed to examine the vertical meridian at $2^{\circ}$ intervals between $14^{\circ}$ above and $10^{\circ}$ below fixation, passing through the fixation point. Two points, each lying $1^{\circ}$ on either side of the vertical meridian, were examined for each location and their average taken as the retinal sensitivity at that location. Patients who had more than two errors in the total error score (defined as the sum of fixation losses and positive and negative error scores) were excluded.

Our control group consisted of 27 age-matched patients attending for problems that did not interfere with their visual field analysis (e.g. ocular motility problems and dry eyes without corneal involvement). The average sensitivity at each location on the visual field of the study group was compared with that of the control group using Student's $t$-test. Collective rather than individual results were used in the analysis to minimise the effect of short-term fluctuation in retinal sensitivity usually found when assessing pathological scotomata. ${ }^{16.17}$ The study group results were further analysed employing Student's $t$-test, by comparing the results of those with short and those with long operating times with the results of the control group. The same procedure was applied for analysing the preextraction and the post-extraction time subgroups. Fourteen patients from the study group underwent an identical test 10 weeks (average) following surgery in order to determine whether spontaneous improvement in visual function takes place, and the results were compared with their initial post-operative results.

Correlation coefficients for each point in the visual field with the total operating time, the pre-extraction time and the post-extraction time were calculated and their significance assessed by the $t$-test. Similar comparisons were made between the best corrected visual acuity and each of the total operating times and the pre-extraction and postextraction times.

\section{RESULTS}

Thirty-six patients ( 12 men and 24 women) met all the criteria of the study. Their ages ranged between 54 and 85 years (mean 71.3 years). All but 1 (who received an anterior chamber lens) received posterior chamber intraocular lens implants. The best corrected visual acuities at 2 weeks ranged between $6 / 6$ and $6 / 36$ with 7 patients having a best corrected acuity of worse than $6 / 12$. The fundi of all operated eyes appeared clinically normal at the time of follow-up examination. Operating time varied between 26 and 56 minutes (mean 41.3 minutes). Speculum insertion to nucleus extraction (pre-extraction) time varied between 5 and 20 minutes (mean 13.3) minutes. Nucleus extraction to speculum removal (post-extraction) time varied between 16 and 42 minutes (mean 28 minutes).

The control cohort comprised 9 men and 18 women whose ages ranged between 51 and 86 years (mean 71.6 years). Tables I and II present the results of threshold retinal sensitivity testing for the study and control groups using the program shown in Fig. 1. Fig. 2 shows the average threshold sensitivities for the study and control samples in decibels plotted against the angular separation from the fixation point.

Average threshold sensitivities at points $8^{\circ}$ and $10^{\circ}$ above fixation were significantly lower in the study patients than in the control patients $(p<0.048$ and 0.022 respectively) and the value at $6^{\circ}$ above fixation gave a significance value of $p<0.054$. Comparison of all other points along the meridian failed to show any statistically significant differences between the study and control populations ( $p$ varied between 0.16 and 0.66 ).

The study sample results were sorted according to operating time length and the threshold sensitivity results for long and short operating times (defined as longer and shorter than mean operating time respectively) were compared with those of the control sample (Fig. 3). In the short operating time subgroup none of the points along the vertical meridian was significantly different from the control group ( $p$ varied between 0.18 and 0.98 ) while in the long operating time subgroup the points $12^{\circ}, 10^{\circ}, 8^{\circ}$ and $6^{\circ}$ above fixation displayed significantly lower retinal sensitivities when compared with corresponding points from the control sample $(p=0.021,0.024,0.035$ and 0.039 respectively).

The study sample was also investigated with regard to the pre-extraction and post-extraction times, which were compared with those for the control sample (Fig.4). The results for the long pre-extraction time subgroup were not statistically different at any point along the vertical meridian from those of the control group ( $p$ varied between 0.12 and 0.96 ) while for the long post-extraction time subgroup retinal sensitivities at the points $12^{\circ} .10^{\circ}, 8^{\circ}$ and $6^{\circ}$ above fixation were significantly less than those of the control sample ( $p=0.032,0.024,0.031$ and 0.031 respectively).

Fourteen study patients were examined for a second time 41-92 days after surgery (mean 70 days) during the study period. Fig. 5 shows the average retinal sensitivities for this group at 2 weeks and 10 weeks following surgery plotted against the angular separation from the fixation point. Although the results of this group showed a trend towards improvement of the sensitivity thresholds for nearly all the points along the vertical meridian, this improvement was not statistically significant ( $p$ varied between 0.11 and 0.98 ), nor did it differ significantly from the control group ( $p$ varied between 0.31 and 0.97 ).

Correlation between the operating time and threshold sensitivity for each point along the meridian (Fig. 6), though not reaching statistical significance for any point, was highest for the points $8^{\circ}, 6^{\circ}$ and $4^{\circ}$ degrees above 


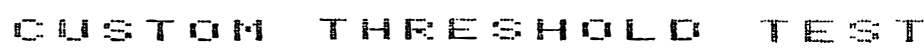

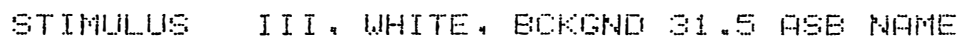
ELIMC SFIT CHEGK GIZE II SFHEIPG FIYHTILH TAFIET DEPTFIHL STFETEG FIILL THEESHOLL

[IFTE DEI-DE-9Z TIME $12: 30: 01$ FIJFIL [IIAHETEF: FY USED UE LUE LEG

\section{R I GHT}
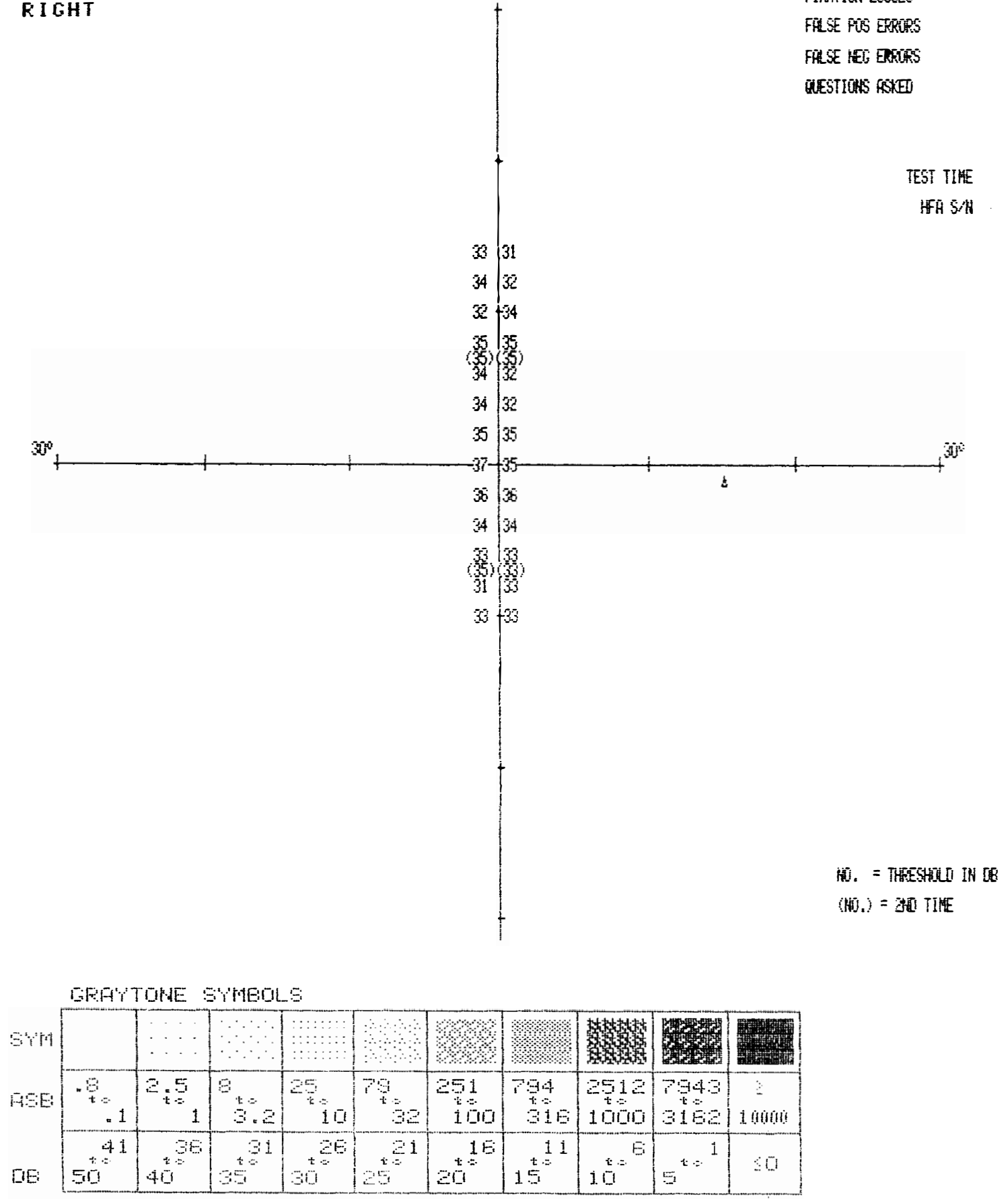

Fig. 1. The results of the visual field examination of a normal subject using the same program used in the study. Retinal threshold sensitivities were tested along a vertical line passing through fixation. The average of the tw'o points at each location was taken as the retinal sensitivity. 
Table I. Results of retinal sensitivity testing of the study group using the program shown in Fig. 1

\begin{tabular}{lccc}
\hline $\begin{array}{l}\text { Location } \\
\text { in degrees } \\
\text { from fixation }\end{array}$ & \multicolumn{3}{c}{ Retinal sensitivity in decibels } \\
\cline { 2 - 4 } & Mean & Median & Standard deviation \\
\hline 14 above & 21.7 & 21.5 & 4.35 \\
12 above & 23.0 & 23.0 & 3.51 \\
10 above & 23.6 & 24.0 & 3.30 \\
8 above & 23.9 & 24.5 & 4.46 \\
6 above & 24.7 & 25.5 & 4.01 \\
4 above & 25.3 & 26.0 & 3.52 \\
2 above & 26.4 & 26.0 & 3.58 \\
Centre & 26.6 & 27.0 & 3.66 \\
2 below & 26.2 & 26.5 & 3.70 \\
4 below & 25.8 & 26.5 & 3.86 \\
6 below & 25.8 & 26.0 & 3.61 \\
8 below & 25.2 & 26.5 & 4.33 \\
10 below & 24.8 & 26.0 & 4.29 \\
\hline
\end{tabular}

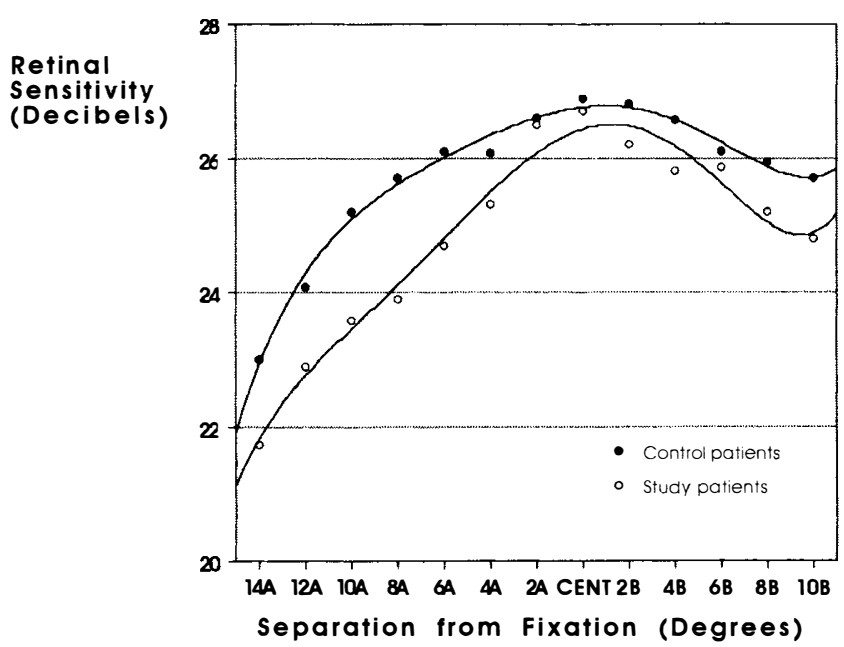

Fig. 2. Average retinal sensitivities for the study and control groups plotted against the angular separation from the fixation point. A, above; $B$, below' Cent, central.

fixation (correlation coefficients $-0.24,-0.22$ and -0.25 respectively). This was also true for the post-extraction time but not for the pre-extraction time (Fig. 6). No statistically significant correlation was found between the best corrected visual acuity and any of the total operating times or the pre-extraction or post-extraction times (correlation coefficients $0.0196,0.231$ and 0.131 respectively).

\section{DISCUSSION}

The above results indicate that operating microscopic light exposure can cause a depression in retinal sensitivity in the absence of any clinically observable lesion. This effect varies directly with operating time and more precisely with the exposure time after nucleus removal.

The site of maximal depression in retinal sensitivity was between $6^{\circ}$ and $12^{\circ}$ above fixation (approximately $2-4 \mathrm{~mm}$ below the foveola). This matches the predicted site of maximal exposure to the illuminating element of the operating microscope (position 3 ) in the experiment of Brod and colleagues ${ }^{15}$ which predicted that the centre of the image of the illuminating element would be focused
Table II. Results of retinal sensitivity testing of the control group using the program shown in Fig. 1

\begin{tabular}{lccc}
\hline \multirow{2}{*}{$\begin{array}{l}\text { Location } \\
\text { in degrees } \\
\text { from fixation }\end{array}$} & \multicolumn{3}{c}{ Retinal sensitivity in decibels } \\
\cline { 2 - 4 } & Mean & Median & Standard deviation \\
\hline 14 above & 23.0 & 23 & 4.26 \\
12 above & 24.1 & 24 & 2.69 \\
10 above & 25.3 & 25 & 2.28 \\
8 above & 25.6 & 26 & 2.10 \\
6 above & 26.2 & 26 & 1.98 \\
4 above & 26.1 & 26 & 1.83 \\
2 above & 26.7 & 27 & 2.09 \\
Centre & 26.9 & 27 & 2.35 \\
2 below & 26.9 & 27 & 2.30 \\
4 below & 26.5 & 27 & 2.19 \\
6 below & 26.1 & 26 & 2.17 \\
8 below & 25.9 & 26 & 2.50 \\
10 below & 25.6 & 26 & \\
\hline
\end{tabular}

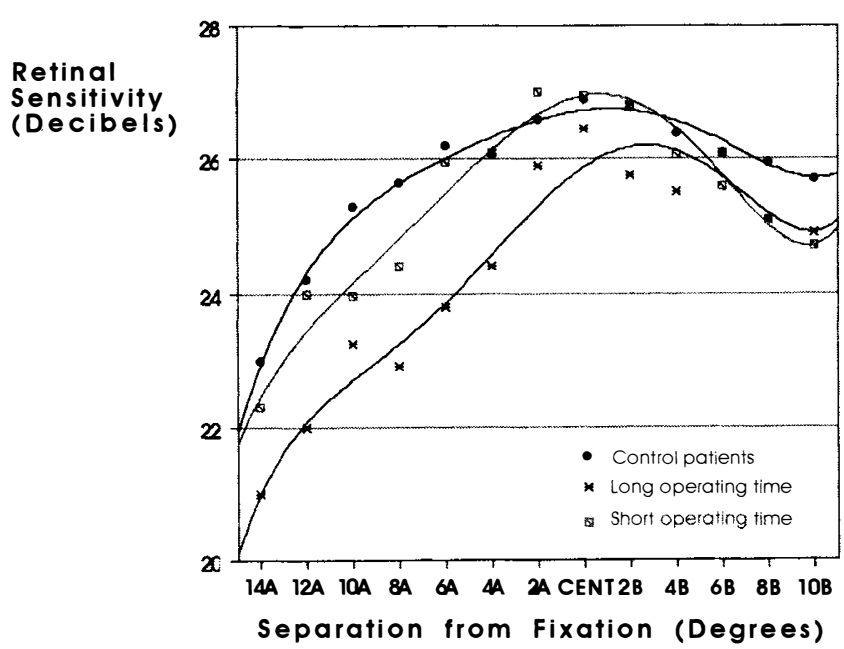

Fig. 3. Average retinal sensitivities for the control group and the long and short operating time subgroups plotted against the angular separation from the fixation point. A, above; B, below'; Cent, central.

$2.0 \mathrm{~mm}$ below the foveola. The effect of operating microscope light was a little further below the foveola in our study, probably because we did not control the extent of inferior rotation of the eye by the bridle suture. This is an understandable variation in view of the varying preferences of different surgeons. An alternative explanation could be the use of the Wild microscope, for which the focus of maximal illumination may differ from that for the Zeiss OpMi 6 used by Brod et al. ${ }^{15}$

To our knowledge this is the first prospective study to utilise static field perimetry to detect a depression in retinal sensitivity after cataract extraction. Berler and Peyser ${ }^{18}$ used visual acuity as a parameter to assess the effect of light on the retina and concluded that reduced visual acuity was consistently more common with highintensity light. This is not in accordance with our results. When we correlated best corrected visual acuity with operating time, pre-extraction and post-extraction times we found no association. This is probably because the operating microscope light was focused away from the foveola in our study. 


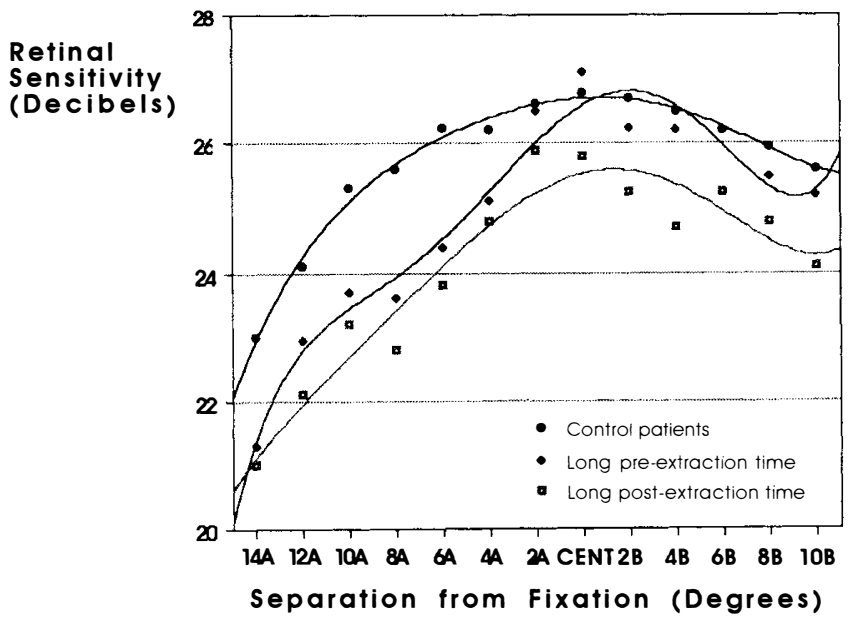

Fig. 4. Average retinal sensitivities for the control group and the long pre-and post-extraction time subgroups plotted against the angular separation from the fixation point. $A$, above; $B$, below; Cent, central.

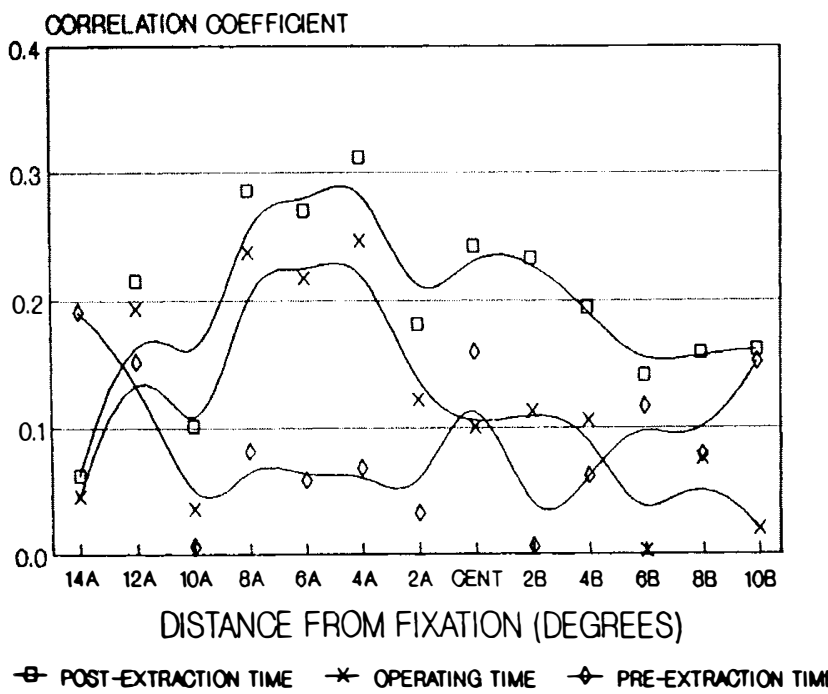

Fig. 6. Correlation coefficient for the retinal sensitivity and each of the operating time, pre-extraction and post-extraction times plotted against vertical distance from fixation. A, above; $\mathrm{B}$, below; Cent, central.

We have found a direct relationship between the duration of surgery and retinal damage. The average operating time in our study group was shorter than that reported for most cases with visible retinal lesions. For example, operating times varied between 75 and 90 minutes in McDonald and Irvine's report,' 55 and 175 minutes in Boldrey et al.'s report ${ }^{2}$ and 75 minutes for both cases in the report of Lindquist et al. ${ }^{6}$ In the case of light damage after refractive surgery reported by Brod et al. ${ }^{10}$ the operating time was approximately 2 hours.

Although the time for which the operating microscope was used did not exceed 15 minutes for the two cases reported by McDonald et al. after pars plana vitrectomy, ${ }^{13}$ the media were clear during that time and the eyes were phakic. Our results show that this factor is probably crucial in determining the extent of operating microscope light damage.

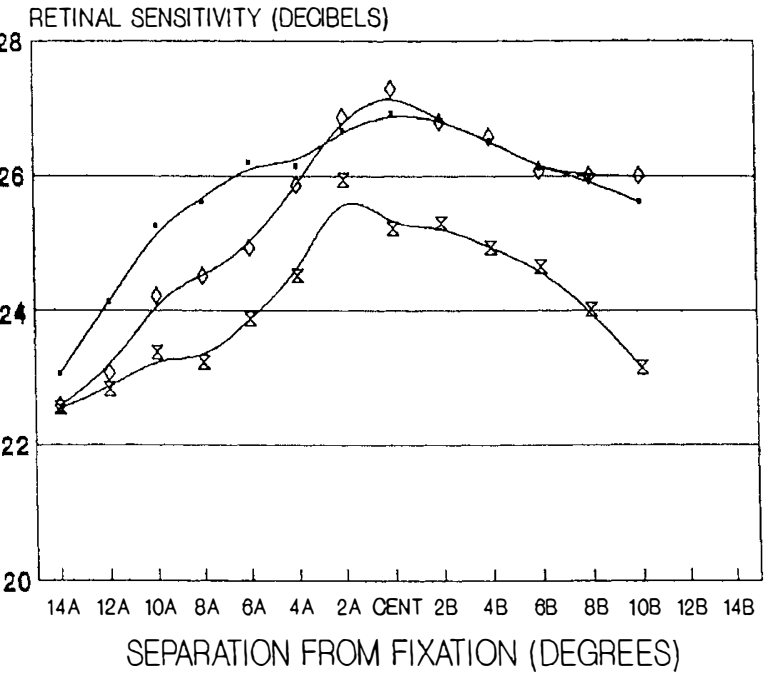

$\rightarrow$ CONTROL PAIENTS $\rightarrow$ TEN WEEKS POST OP. \& TWO WEEKS POST 0

Fig. 5. Average retinal sensitivities for a group of patients tested 2 and 10 weeks following surgery, and for the control group. Improvement in retinal sensitivity, though not statistically significant, is noted. A, above; $B$, below; Cent, central.

The depression of retinal sensitivity was most marked for the long operating times and for the long post-extraction time subgroups. Correlation coefficients between operating time and post-extraction time and retinal sensitivities were highest at the points exposed most to light but not elsewhere (Fig. 6). There is thus a reciprocal relationship between exposure time and retinal sensitivity. This was also established by Robertson and Feldman. ${ }^{19}$ The lack of statistical significance of correlation coefficient for the relevant points can partially be explained by the lateral displacement of the eye during surgery. A significant number of the operating microscope light-related lesions reported in the literature have been found away from the vertical meridian. ${ }^{15}$ It may be argued that the use of a wider vertical profile (e.g. four instead of two lines wide) could have detected such cases. This would have led to unduly long examination times and consequently higher chances for observer error, which was a major cause of exclusion of patients in our study.

We found also that retinal sensitivities at all points on the vertical profile improved with time in the group reexamined 10 weeks after surgery. The improvement was not, however, statistically significant. Lindquist et al. ${ }^{6}$ documented marked recovery of paramacular scotomas a few months following light-induced maculopathy noticed after surgery in 2 of their cataract patients.

We conclude that operating microscope light damage can occur even with fairly short operating times. Measures to minimise the damage should include minimising exposure time, and using different methods proposed in the literature such as corneal occluders, light filters, non-coaxial oblique illumination ${ }^{1-3,5,10-12,14,20-28}$ and moving the focused beam of light away from the foveola by manipulating the eye, the operating microscope and centration according to the guidelines given by Brod and colleagues, ${ }^{15}$ i.e. tilting the eye downwards, tilting the micro- 
scope towards the surgeon and centring the microscope light over the pupil and not the wound.

It would have been ideal for the patients to have acted as their own controls but the density of cataract pre-operatively was very marked in the majority of cases, resulting in significantly reduced visual function. It was therefore necessary to assemble a separate control population.

The authors have no proprietary interest in the development or marketing of any equipment used in this study.

The authors are grateful to Drs J. Williamson, D. W. Doig and P. M. Kyle of the Eye Department at the Southern General Hospital for allowing us to recruit their patients for this study.

Key words: Operating microscope retinopathy, Phototoxicity, Retinal light damage, Static perimetry.

\section{REFERENCES}

1. McDonald HR, Irvine AR. Light induced maculopathy from the operating microscope in extracapsular cataract extraction and intraocular lens implantation. Ophthalmology 1983;90:945-51.

2. Boldrey EE, Ho BT, Griffith RD. Retinal burns occurring at cataract extraction. Ophthalmology 1984;91:1297-302.

3. Ross WH. Light induced maculopathy. Am J Ophthalmol 1984;98:488-93.

4. Khwarg SG, Geoghegan M, Hanscom TA. Light induced maculopathy from the operating microscope. Am J Ophthalmol 1984;98:628-30.

5. DeLaey JJ, De Wachter A, Van Oye R, Verbraeken H. Retinal phototrauma during intraocular lens implantation. Int Ophthalmol 1984;7:109-16.

6. Lindquist TD, Grutzmacher RD, Gofman JD. Light induced maculopathy: potential for recovery. Arch Ophthalmol 1986; 104:1641-7.

7. Cech JM, Choromokos EA, Sanitato JA. Light induced maculopathy following penetrating keratoplasty and lens implantation. Arch Ophthalmol 1987;105:751.

8. Hupp SL. Delayed incomplete recovery of macular function after photic retinal damage associated with extracapsular cataract extraction and posterior lens insertion. Arch Ophthalmol 1987; 105:1022-3.

9. Johnson RN, Schatz H, McDonald HR. Photic maculopathy: early angiographic and ophthalmoscopic findings and late development of choroidal folds. Arch Ophthalmol 1987;105:1633-4.

10. Brod RD, Barron BA, Sueflow JA, Franklin RM, Packer AJ. Phototoxic retinal damage during refractive surgery. Am J Ophthalmol 1986;102:121-3.

11. Khwarg SG, Linstone FA, Daniels SA, Isenberg SJ, Hans- con TA, Geoghegan M, Straatsma BR. Incidence, risk factors and morphology in operating microscope light retinopathy. Am J Ophthalmol 1987;103:255-63.

12. Stamler JF, Blodi CF, Verdier D, Krachmer JH. Microscope light induced maculopathy in combined penetrating keratoplasty, extracapsular cataract extraction and intraocular lens implantation. Ophthalmology 1988;95:1142-6.

13. McDonald HR, Harris MJ. Operating microscope induced retinal phototoxicity during pars plana vitrectomy. Arch Ophthalmol 1988;106:521-3.

14. Brod RD, Ball SF, Packer AJ. A model for predicting the site of paraxial retinal lesions secondary to 'coaxial' operating microscope illumination systems. Am J Ophthalmol 1987; 104:516-23.

15. Brod RD, Olsen MD, Ball SF, Packer AJ. The site of operating microscope light induced injury on the human retina. Am J Ophthalmol 1989;107:390-7.

16. Flammer J, Drance SM, Zulauf M. Differential light threshold: short- and long-term fluctuation in patients with glaucoma, normal control and patients with suspected glaucoma. Arch Ophthalmol 1984;102:704-6.

17. Haefliger IO, Flammer J. Fluctation of the differential light threshold at the border of absolute scotomas. Ophthalmology 1991;98:1529-32.

18. Berler DK, Peyser R. Light intensity and visual acuity following cataract surgery. Ophthalmology 1983;90:933-6.

19. Robertson DM, Feldman RB. Photic retinopathy from the operating room microscope. Am J Ophthalmol 1986;101:561-9.

20. Willig JL, Zaffuto S. A simple method for corneal and retinal protection during cataract surgery. Am J Ophthalmol 1984;97:532.

21. Schwartz LK, Norris JL. A corneal shield to prevent light induced maculopathy during cataract surgery. Am J Ophthalmol 1984;97:658-9.

22. McIntyre DJ. Phototoxicity: the eclipse filter. Ophthalmology 1985;92:364-5.

23. Fechner PU, Barth R. Effect on the retina of an air cushion in the anterior chamber and coaxial illumination. Am J Ophthalmol 1983;96:600-4.

24. Aymond DK. Retinal burns occurring at cataract extraction [correspondence]. Ophthalmology 1985;92:715-6.

25. Calkins JL, Hochheimer BF, D’Anna SA. Potential hazards from specific ophthalmic devices. Vision Res 1980;20: 1039-53.

26. Nevyas HJ, Nevyas JY. Surgical corneal light occluder made of black hema. Ophthalmic Surg 1985;16:696-8.

27. Colvard DM. Operating microscope light induced retinal injury: mechanisms, clinical manifestations and preventive measures. Am Intraocul Implant Soc J 1984;10:438-43.

28. Sliney DH. Eye protective techniques for bright light. Ophthalmology 1983;90:937-44. 